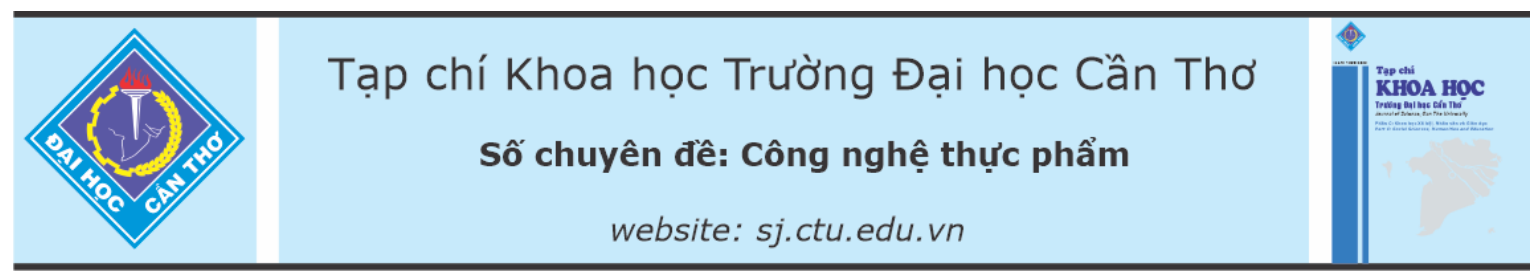

DOI:10.22144/ctu.jsi.2021.021

\title{
NGHIÊN CÚU ĐIỀU KIỆN CHIẾT XUẤT NARINGIN TÙ VỎ BƯỞI NĂM ROI (Citrus grandis (L.) OSBECK)
}

Lý Thị Thùy Duyên ${ }^{1}$, Mai Kim Ngân ${ }^{1}$, Bùi Hoàng Đăng Long ${ }^{1}$, Bạch Long Giang ${ }^{2}$, Trần Quốc Toàn ${ }^{3}$, Kha Chấn Tuyền ${ }^{4}$, Nguyễn Văn Ây ${ }^{5}$ và Huỳnh Xuân Phong ${ }^{1 *}$

${ }^{l}$ Viện Nghiên cứu và Phát triển Công nghệ Sinh học, Truờng Đại học Cần Tho

${ }^{2}$ Viện Kỹ thuật Công nghệ cao, Truờng Đại học Nguyễn Tất Thành

${ }^{3}$ Viện Hóa hoc các Hợp chất thiên nhiên, Viện Hàn lâm Khoa học và Công nghệ Việt Nam

${ }^{4}$ Khoa Công nghệ Thưc phẩm, Truờng Đại học Nông lâm TP. HCM

${ }^{5}$ Khoa Nông Nghiệp, Truoòng Đại học Cần Tho

*Nguoòi chịu trách nhiệm bài viết: Huỳnh Xuân Phong (email: hxphong@ctu.edu.vn)

\section{Thông tin chung:}

Ngày nhận bài: $23 / 02 / 2021$

Ngày nhận bài sủa: 12/03/2021

Ngày duyệt đăng: 28/04/2021

Title:

Study on the conditions for extracting of naringin from pomelo peels (Citrus grandis (L.) Osbeck)

\section{Tù khóa:}

Citrus grandis, naringin, phuoong pháp ngâm, phuoong pháp Soxhlet, vỏ buơoi

\section{Keywords:}

Citrus grandis, immersion method, naringin, pomelo peels, Soxhlet method

\begin{abstract}
Naringin is a flavonoid glycoside found with high levels in pomelo peels. Naringin has many good effects for human health such as antioxidant activity, cholesterol reduction, prevention of high blood pressure, etc. This study is aimed to investigate the conditions for extraction of naringin from pomelo peels. The research was carried out to select the appropriate conditions for naringin extraction including the ratio of ethanol and water (100:0, 80:20, $70: 30 \mathrm{v} / \mathrm{v})$, soaking time $(0.5,1.0,1.5$ hours $)$, ratio of sample and solvent $(1: 10,1: 12,1: 14,1: 16 \mathrm{w} / \mathrm{v}$ ), extraction time for immersion method (from 0,5 to 5 hours) and for Soxhlet method (from 0,5 to 7 hours). The optimal extraction conditions of naringin from Nam Roi pomelo peels were determined as followed: the ratio of ethanol and water at 80:20 v/v, the soaking time of 1.5 hours, the ratio of sample and solvent at 1:14 w/v, the extraction time of 3.5 hours for the immersion method and 5.5 hours for the Soxhlet method. The highest naringin concentrations were achieved at 0.0879 $\pm 0,0021 \mathrm{mg} / \mathrm{mL}$ and $3.9157 \pm 0,0921 \mathrm{mg} / \mathrm{mL}$, respectively.
\end{abstract}

\section{TÓM TÁ̀T}

Naringin là một flavonoid glycoside được tìm thấy với hàm lượng cao trong vỏ bười có tác dụng nhu kháng oxy hóa, giảm cholesterol, ngăn ngìa cao huyết áp,... Nghiên cưu này được tiến hành nhằm chọn các điều kiện chiết xuất naringin thich hợp tù̀ nguồn phụ phẩm vỏ bưởi. Nghiên cứu khảo sát tỷ lệ ethanol và nước (100:0; 80:20; 70:30 v/v), thời gian ngâm $(0,5 ; 1,0 ; 1,5$ giò), tỉ lệ mẫu và dung môi (1:10; 1:12; 1:14; 1:16 w/v), thời gian chiết xuất được ghi nhận sau mỗi 0,5 giờ đến 5 giờ đối với phương pháp ngâm và đến 7 giờ đối với phuơng pháp Soxhlet. Kết quả chiết xuất naringin tù vỏ bươi Năm Roi cho thấy tỷ lẹ ethanol và nước (80:20 v/v), thời gian ngâm là 1,5 giờ, tý lẹ mẫu và dung môi $(1: 14$ w/v), thời gian chiết xuất là 3,5 giờ đối với phuơng pháp ngâm và 5,5 giờ đối với phuơng pháp Soxhlet, hàm luợng naringin đạt được giá trị cao nhất tương úng là 0,0879 $\pm 0,0021 \mathrm{mg} / \mathrm{mL}$ và 3,9157 $\pm 0,0921$ $m g / m L$. 


\section{GIỚI THIỆU}

Bưởi Năm Roi (Citrus grandis (L.) Osbeck) được trồng phổ biến ở Việt Nam, đặc biệt là Tây Nam Bộ, điển hình là Vĩnh Long, Bến Tre, Cần Thơ, Hậu Giang. Trong bưởi chứa nhiều flavonoid. Theo Lu et al. (2006), các flavonoid thường được phân thành hai nhóm: flavanone glycoside (naringin, hesperidin, neohesperidin,...) và polymethoxylated flavones (noniletin, sinensetin, tangeretin,...). Trong phần trắng của vỏ bưởi chứa nhiều naringin. Naringin là flavanone glycoside thuộc nhóm flavonoid, là sắc tố trong không bào thực vật, tan trong dung môi phân cực, quyết định đến màu của quả (Ghasemzadeh \& Ghasemzadeh, 2011). Theo Kanaze et al. (2006), naringin được tìm thấy với hàm lượng cao trong vỏ bưởi với tác dụng như kháng oxy hóa, giảm cholesterol, ngăn ngừa cao huyết áp, giảm tai biến tim mạch, phòng chống ung thư,...

Hiện nay, naringin đã được sản xuất và thương mại hóa dưới dạng tinh chất được dùng trong dược phẩm cũng như thực phẩm với giá thành cao, bên cạnh đó trữ lượng vỏ bưởi ở nước ta rất lớn, nếu khai thác tốt nguồn nguyên liệu này, sẽ giải quyết được nhu cầu và giảm giá thành thuốc có chứa hoạt chất naringin. Từ đó, việc nghiên cứu điều kiện ly trích naringin từ vỏ bưởi là cần thiết nhằm có thể tận dụng phụ phẩm vỏ bưởi, tránh lãng phí đồng thời có thể thu nguồn naringin có giá rẻ hơn, tạo điều kiện người dân có cơ hội chăm sóc sức khỏe tốt hơn, giảm sự phụ thuộc vào nguồn cung từ nước ngoài, đặc biệt là trong sản xuất dược phẩm.

\section{VẬT LIỆU VÀ PHƯƠNG PHÁP NGHIÊN CÚU}

\subsection{Nguyên vật liệu và hóa chất}

Vỏ bưởi Năm Roi và Da Xanh được thu thập ở quận Ninh Kiều, thành phố Cần Thơ. Phần trắng của vỏ bưởi Năm Roi và bưởi $\mathrm{Da}$ Xanh được cắt nhỏ, sấy ở $65^{\circ} \mathrm{C}$ trong 24 giờ, sau đó nghiền thành bột mịn và trữ ở nhiệt độ phòng cho các thí nghiệm tiếp theo. Sắc ký bản mỏng sử dụng giấy sắc ký TLC Silica gel 60 (Merck, Đức). Các hóa chất chính bao gồm ethanol 99,9\% (EMSURE, Merck KGaA, Đức), ethylene glycol - EG (Merck, Đức), $\mathrm{NaOH}$ (Merck, Đức) và naringin (Sigma-Aldrich, Đức).

\subsection{Phương pháp nghiên cứu}

\subsubsection{Xác định hàm lương naringin tù vỏ buoơi}

Thí nghiệm được thực hiện với mục đích là xác định hàm lượng naringin tổng có vỏ bưởi Năm Roi, đồng thời so sánh hàm lượng naringin từ vở bưởi $\mathrm{Da}$ Xanh. Vỏ bưởi Năm Roi và $\mathrm{Da}$ Xanh sau khi được sấy khô và xay nhuyễn. Cân bột bưởi $\mathrm{Da}$ Xanh và
Năm Roi, mỗi loại $15 \mathrm{~g}$ sau đó mẫu được chiết xuất với $150 \mathrm{~mL}$ ethanol $80 \%$, trong 30 phút với nhiệt độ $80^{\circ} \mathrm{C}$. Hàm lượng naringin được xác định bằng cách sử dụng $50 \mu \mathrm{L}$ dịch chiết xuất và bổ sung ethanol 99,9\% đến $10 \mathrm{~mL}$, tiến hành đo độ hấp thụ ở bước sóng $283 \mathrm{~nm}$ theo phương pháp của Kuntíc et al. (2012). Naringin chuẩn được pha trong ethanol $99,9 \%$ ở nồng độ $0,2 \mathrm{mg} / \mathrm{mL}$. Đường chuẩn được chuẩn bị bằng cách pha loãng dung dịch gốc để tạo ra các dung dịch có nồng độ từ $0,02-0,004 \mathrm{mg} / \mathrm{mL}$ và được đo với bước sóng $283 \mathrm{~nm}$.

\subsubsection{Khảo sát ảnh huơong của nồng độ ethanol đến hàm luợng naringin tổng}

Mục đích của thí nghiệm là khảo sát ảnh hưởng của nồng độ ethanol đến hàm lượng naringin tổng trích ly được trong vỏ bưởi. Cân $15 \mathrm{~g}$ bột vỏ bưởi (loại vỏ bưởi được chọn ở thí nghiệm 2.2.1), bổ sung $150 \mathrm{~mL}$ ethanol để chiết xuất trong 30 phút ở nhiệt độ $80^{\circ} \mathrm{C}$. Nồng độ ethanol sử dụng lần lượt là $70 \%$, $80 \%$ và $99,9 \%$ ở cả phương pháp ngâm và phương pháp Soxhlet. Hàm lượng naringin được xác định theo phương pháp của Kuntíc et al. (2012) như đã mô tả ở trên.

\subsubsection{Khảo sát ảnh hương của thời gian ngâm mẫu đến hàm lượg của naringin tổng}

Thí nghiệm được thực hiện với mục đích là khảo sát ảnh hưởng của thời gian ngâm mẫu trong dung môi ở nhiệt độ phòng đến hàm lượng của naringin tổng được chiết xuất. Cân $15 \mathrm{~g}$ bột bưởi sau đó ngâm với $150 \mathrm{~mL}$ ethanol với nồng độ được chọn ở nội dung 2.2.2. trong 0,$5 ; 1,0 ; 1,5$ giờ ở nhiệt độ phòng. Sau đó chiết xuất trong 30 phút và nhiệt độ $80^{\circ} \mathrm{C}$ ở cả phương pháp ngâm và phương pháp Soxhlet.

\subsubsection{Khảo sát ảnh hưởng của tỷ lệ mẫu và dung môi đến hàm luợng naringin tổng}

Thí nghiệm được thực hiện với mục đích là khảo sát tỷ lệ mẫu và dung môi đến hàm lượng naringin tổng. Cân $15 \mathrm{~g}$ mẫu sau đó ngâm vào dung môi với tỷ lệ mẫu và dung môi là $1: 10 ; 1: 12 ; 1: 14 ; 1: 16 \mathrm{~g} / \mathrm{mL}$ với nồng độ dung môi được chọn ở nội dung 2.2.2, ngâm ở nhiệt độ phòng với thời gian được chọn ở thí nghiệm 2.2.3, trích trong 30 phút và nhiệt độ $80^{\circ} \mathrm{C}$ ở cả phương pháp ngâm và phương pháp Soxhlet.

\subsubsection{Khảo sát ảnh hương của thời gian trích đến hàm lượng naringin tổng}

Thí nghiệm được thực hiện với mục đích là khảo sát ảnh hưởng của thời gian chiết xuất đến hàm lượng naringin tổng. Cân $15 \mathrm{~g}$ mẫu sau đó ngâm vào dung môi với tỉ lệ mẫu và dung môi được chọn ở nội dung 2.2.4, nồng độ dung môi được chọn ở nội dung 2.2.2 sau đó ngâm ở nhiệt độ phòng với thời gian 
được chọn ở nội dung 2.2.3 và chiết xuất ở nhiệt độ $80^{\circ} \mathrm{C}$ từ 0,5 đến 5,0 giờ đối với phương pháp ngâm và từ 0,5 đến 7,0 giờ đối với phương pháp Soxhlet.

\subsubsection{Xác định hàm lượng naringin trong dung dịch chiết xuất}

Thí nghiệm được thực hiện với mục đích nhằm xác định được hàm lượng naringin trong dịch chiết xuất bằng phương pháp sắc ký bản mỏng (TLC, Thin Layer Chromatography) với dung môi sắc ký là ethyl acetate: acetic acid: nước (10:2:1) (Hounghton \& Ramam, 1998). Sau khi sắc ký, mẫu được soi dưới đèn $U_{254 n m}$ và đánh dấu vị trí. Cạo lấy phần silicagel đã dược đánh dấu vào ống eppendorf, cho thêm $1 \mathrm{~mL}$ ethanol và ly tâm ở 2.400 vòng/phút trong 20 phút. Hút phần dịch trong phía trên để đo giá trị $\mathrm{OD}_{283 n m}$, qua đó xác định được hàm lượng naringin thực.

\subsection{Phân tích số liệu và xử lý kết quả}

Kết quả được xử lý và vẽ biểu đồ bằng phần mềm Microsoft Excel 2013 (Microsoft Corporation, USA). Số liệu được xử lý thống kê bằng chương trình Statgraphics Centurion XVI (Statpoint Technologies, Inc., USA).

\section{KẾT QUẢ VÀ THẢO LUẬN}

\subsection{Xác định hàm lượng naringin từ vỏ bưởi Năm Roi và Da Xanh}

Kết quả chiết xuất ở $80^{\circ} \mathrm{C}$ trong 30 phút cho thấy hàm lượng naringin tổng thu được từ bưởi Năm Roi $(1,2452 \pm 0,0558 \mathrm{mg} / \mathrm{mL})$ cao hơn khoảng $76,53 \%$ so với bưởi $\mathrm{Da}$ Xanh (hàm lượng naringin tổng chỉ đạt $0,7051 \pm 0,0749 \mathrm{mg} / \mathrm{mL}$ ) (Hình 1) và khác biệt có ý nghĩa thống kê với độ tin cậy $95 \%$. Nhiều nghiên cứu cho thấy sự hiện diện của naringin trong vỏ của các loại cây có múi, đặc biệt là trong vỏ bưởi như Ahmeda et al. (2019), Bacanli et al. (2015), Nguyễn Hoài Thương và ctv. (2016), ... Kết quả này cho thấy vỏ bưởi Năm Roi là nguồn nguyên liệu thích hợp hơn để ly trích naringin so với bưởi $\mathrm{Da}$ Xanh nên vỏ bưởi Năm Roi được sử dụng để khảo sát các điều kiện ly trích.

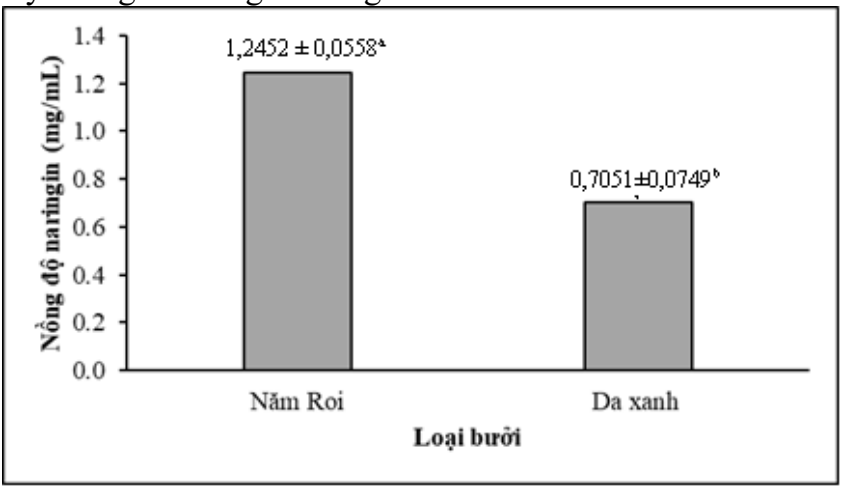

Hình 1. Nồng độ naringin tổng thu được từ vỏ bưởi Năm Roi và bưởi Da Xanh

\section{2. Ảnh hưởng của nồng độ ethanol đến hàm lượng naringin tổng}

Hàm lượng naringin được chiết xuất với các nồng độ khác nhau của ethanol đạt cao nhất khi vỏ bưởi được chiết xuất với nồng độ ethanol $80 \%$ cho cả hai phương pháp (Bảng 1 ), hàm lượng naringin thu được tương ứng là $0,0573 \pm 0,0031 \mathrm{mg} / \mathrm{mL}$ và $1,1955 \pm 0,0768 \mathrm{mg} / \mathrm{mL}$. Hàm lượng naringin thu được trong thử nghiệm này tương tự với kết quả nghiên cứu của Zarina et al. (2013). Đối với phương pháp Soxhlet, mặc dù hàm lượng naringin khi chiết xuất với ethanol $70 \%$ và $80 \%$ khác biệt không có ý nghĩa về mặt thống kê, tương ứng với hàm lượng naringin lần lượt là $1,1652 \pm 0,0362 \mathrm{mg} / \mathrm{mL}$ và $1,1955 \pm 0,0768 \mathrm{mg} / \mathrm{mL}$, tuy nhiên, với thể tích nước nhiều sẽ không có lợi cho việc cô đặc ở các bước xử lý tiếp theo nên nồng độ ethanol $80 \%$ là sự lựa chọn thích hợp.

Bảng 1. Nồng độ naringin tổng thu được khi được chiết xuất với nồng độ ethanol khác nhau bằng phương pháp ngâm và phương pháp Soxhlet

\begin{tabular}{crr}
\hline \multirow{2}{*}{$\begin{array}{c}\text { Tỷ lệ } \\
\text { ethanol và } \\
\text { nước }\end{array}$} & \multicolumn{2}{c}{$\begin{array}{r}\text { Hàm lượng naringin tổng thu } \\
\text { được }(\mathbf{m g} / \mathbf{m L})\end{array}$} \\
\cline { 2 - 3 } & $\begin{array}{r}\text { Phương pháp } \\
\text { ngâm }\end{array}$ & $\begin{array}{r}\text { Phương pháp } \\
\text { Soxhlet }\end{array}$ \\
\hline $99,9: 0$ & $0,0358 \pm 0,0028^{\mathrm{b}}$ & $0,9582 \pm 0,0911^{\mathrm{b}}$ \\
$80: 20$ & $0,0573 \pm 0,0031^{\mathrm{a}}$ & $1,1955 \pm 0,0768^{\mathrm{a}}$ \\
$70: 30$ & $0,0368 \pm 0,0026^{\mathrm{b}}$ & $1,1652 \pm 0,0362^{\mathrm{a}}$ \\
\hline
\end{tabular}

Ghi chú: \pm : sai số chuẩn; các giá trị trung bình trong cùng một cột theo sau có mẫu tư giống nhau thể hiện sụ khác biệt không có ý nghĩa về mặt thông kê với độ tin cậy $95 \%$. 


\section{3. Ảnh hưởng của thời gian ngâm mẫu đến hàm lượng naringin tổng}

Nồng độ naringin khi ngâm mẫu trong dung môi ở nhiệt độ phòng với các mốc thời gian là 0,$5 ; 1,0$; 1,5 giờ của hai phương pháp được thể hiện ở Bảng 2. Hàm lượng naringin thu được cao nhất khi ngâm trong 1,5 giờ trước khi chiết xuất đối với cả 2 phương pháp, $0,0645 \pm 0,0004 \mathrm{mg} / \mathrm{mL}$ đối với phương pháp ngâm và $1,2733 \pm 0,0138 \mathrm{mg} / \mathrm{mL}$ đối với phương pháp Soxhlet. Động lực của quá trình chiết xuất là do sự chênh lệnh gradiant nồng độ giữa thành phần chiết xuất trong mẫu và dung môi. Sự vận chuyển chất tan từ bên trong tế bào ra bên ngoài dung môi qua con đường khuyếch tán là chủ yếu. Sự khuếch tán này sẽ giúp cho quá trình chiết xuất các chất từ trong nguyên liệu vào dung môi xảy ra nhanh và triệt để hơn, nên việc ngâm mẫu càng lâu giúp chiết xuất nhều hơn, làm giảm được chi phí năng lượng trong quá trình chiết xuất sau đó. Chew et al. (2011) đã ghi nhận nồng độ polyphenol và flavonoid không thay đổi khi ngâm từ 1 đến 2 giờ và giảm khi tăng thời gian ngâm do sự oxy hóa các hợp chất polyphenol bởi ánh sáng và oxy. Kết quả này cũng phù hợp với nghiên cứu của Nguyễn Hoài Thương và ctv. (2016) khi chiết xuất naringin từ vỏ bưởi.

Bảng 2. Hàm lượng naringin tổng được chiết xuất ở các thời gian ngâm mẫu khác nhau

\begin{tabular}{crr}
\hline \multirow{2}{*}{$\begin{array}{c}\text { Thời gian } \\
\text { ngâm } \\
\text { (giờ) }\end{array}$} & \multicolumn{2}{c}{$\begin{array}{r}\text { Hàm lượng naringin tổng } \\
\text { (mg/mL) }\end{array}$} \\
\cline { 2 - 3 } & $\begin{array}{r}\text { Phương pháp } \\
\text { ngâm }\end{array}$ & $\begin{array}{r}\text { Phương pháp } \\
\text { Soxhlet }\end{array}$ \\
\hline 0,5 & $0,0446 \pm 0,0021^{\mathrm{c}}$ & $0,9008 \pm 0,0125^{\mathrm{b}}$ \\
1,0 & $0,0587 \pm 0,0036^{\mathrm{b}}$ & $0,9581 \pm 0,0201^{\mathrm{b}}$ \\
1,5 & $0,0645 \pm 0,0004^{\mathrm{a}}$ & $1,2733 \pm 0,0138^{\mathrm{a}}$ \\
\hline
\end{tabular}

Ghi chú: \pm : sai số chuẩn; các giá trị trung bình trong cùng một cột theo sau có mẫu tư giống nhau thể hiện sự khác biệt không có ý nghĩa về mặt thống kê với độ tin cây $95 \%$.

\section{4. Ảnh hưởng của tỷ lệ mẫu và dung môi đến hàm lượng naringin tổng}

Naringin tổng được chiết xuất ở các tỷ lệ mẫu và dung môi khác nhau đạt được hàm lượng cao nhất ở tỷ lệ $1: 14$ cho cả hai phương pháp (Bảng 3 ), kết quả này tương tự với nghiên cứu của Nguyễn Hoài Thương và ctv. (2016). Hàm lượng naringin thu được tương ứng với tỷ lệ mẫu và dung môi này là $0,0660 \pm 0,0002 \mathrm{mg} / \mathrm{mL}$ đối với phương pháp ngâm và $1,7987 \pm 0,0939 \mathrm{mg} / \mathrm{mL}$ đối với phương pháp Soxhlet. Điều này có thể giải thích là khi chiết xuất mẫu với lượng dung môi thấp đồng nghĩa với việc mẫu không được chiết xuất hết do gradient nồng độ bên ngoài cao hơn bên trong tế bào, nhưng khi tăng lượng dung môi thì sự chênh lệch gradiant nồng độ càng lớn dẫn đến khả năng khuếch tán tăng. Khi tăng tới một thể tích nào đó, nồng độ chất không tăng nữa mà chỉ tốn dung môi. Đồng thời do nồng độ naringin bị thay đổi bởi thể tích dung môi nên khi tăng lượng dung môi thì nồng độ chất trong dịch chiết xuất sẽ bị pha loãng cũng như xảy ra sự khuyếch tán của các tạp chất khác từ trong vỏ bưởi.

Bảng 3. Hàm lượng naringin tổng được chiết xuất ở các tỷ lệ mẫu và dung môi khác nhau

\begin{tabular}{crr}
\hline \multirow{2}{*}{$\begin{array}{c}\text { Tỷ lệ mẫu } \\
\text { và dung } \\
\text { môi }\end{array}$} & \multicolumn{2}{c}{$\begin{array}{r}\text { Hàm lượng naringin tổng } \\
(\mathbf{m g} / \mathbf{m L})\end{array}$} \\
\cline { 2 - 3 } & $\begin{array}{r}\text { Phương pháp } \\
\text { ngâm }\end{array}$ & $\begin{array}{r}\text { Phương pháp } \\
\text { Soxhlet }\end{array}$ \\
\hline $1: 10$ & $0,0517 \pm 0,0125^{\mathrm{b}}$ & $1,4771 \pm 0,0561^{\mathrm{b}}$ \\
$1: 12$ & $0,0513 \pm 0,0039^{\mathrm{b}}$ & $1,5853 \pm 0,0471^{\mathrm{b}}$ \\
$1: 14$ & $0,0660 \pm 0,0002^{\mathrm{a}}$ & $1,7987 \pm 0,0939^{\mathrm{a}}$ \\
$1: 16$ & $0,0353 \pm 0,0014^{\mathrm{c}}$ & $0,3867 \pm 0,0433^{\mathrm{c}}$ \\
\hline
\end{tabular}

Ghi chú: \pm : sai số chuẩn; các giá trị trung bình trong cùng một cột theo sau có mẫu tư giống nhau thể hiện sư khác biệt không có ý nghĩa về mặt thông kê với độ tin cây $95 \%$.

\section{5. Ảnh hưởng của thời gian chiết xuất đến hàm lượng naringin tổng}

Hàm lượng naringin tổng được chiết xuất ở các mốc thời gian khác nhau đạt được hàm lượng cao nhất ở 3,5 giờ đối với phương pháp ngâm (hàm lượng naringin đạt mức $0,0879 \pm 0,0021 \mathrm{mg} / \mathrm{mL}$ ) và 5,5 giờ đối với phương pháp Soxhlet (hàm lượng naringin đạt mức $3,9157 \pm 0,0879 \mathrm{mg} / \mathrm{mL}$ ) và có sự khác biệt có ý nghĩa thống kê với độ tin cậy $95 \%$ so với hàm lượng naringin tương ứng với các thời gian chiết xuất khác (Bảng 4). Thời gian chiết xuất càng dài thì hàm lượng naringin thu được càng tăng, từ đó có thể thấy thời gian ảnh hưởng rất lớn đến hiệu suất thu hồi. Tuy nhiên, sau khi đạt được đến hàm lượng tối đa thì nồng độ naringin giảm mạnh từ 4 giờ đối với phương pháp ngâm, 6 giờ đối với phương Soxhlet và sau đó gần như không thay đổi với các giờ tiếp theo, kết quả này tương tự với nghiên cứu cùa Niawant et al. (2009).

Nguyễn Hoài Thương và ctv. (2016) cũng ghi nhận sự giảm mạnh của hàm lượng naringin khi tăng thời gian chiết xuất mẫu. Việc giảm của naringin có thể giải thích là các chất chống oxy hóa tự nhiên có thể bị mất đi đáng kể trong quá trình đun nóng lâu trong khi chiết xuất. Thực tế là hầu hết các hợp chất có hoạt tính sinh học tương đối không ổn định khi tiếp xúc với nhiệt. Rawson et al. (2011) đã phát hiện 
ra rằng hầu hết các hợp chất có hoạt tính sinh học trong thực vật như flavonoid, phenolic, chất chống oxy hóa, carotenoid và vitamin $\mathrm{C}$ sẽ thay đổi cấu trúc hóa học và vật lý của chúng cũng làm mất hoạt tính sinh học do quá trình phân hủy nhiệt khi tiếp xúc với nhiệt độ cao, bên cạnh đó còn do sự oxy hóa các gốc phenol của naringin bởi các polyphenol oxidase tạo ra các hợp chất melanin có màu nâu.
Ngoài ra, hiệu suất chiết xuất của phương pháp Soxhlet cao hơn so với phương pháp ngâm là do trong phương pháp Soxhlet, quá trình chiết xuất có sự đảo trộn mẫu liên tục, tạo điều kiện cho mẫu tiếp xúc với dung môi vì thế ảnh hưởng nhiều đến việc tiếp xúc của mẫu với dung môi cũng như được tiến hành ở nhiệt độ cao hơn.

Bảng 4. Hàm lượng naringin tổng được chiết xuất trong 5 giờ đối với phương pháp ngâm và trong 7 giờ đối với phương pháp Soxhlet

\begin{tabular}{crr}
\hline \multirow{2}{*}{$\begin{array}{c}\text { Thời gian chiết xuất } \\
\text { (giờ) }\end{array}$} & \multicolumn{2}{c}{ Hàm lượng naringin tổng (mg/mL) } \\
\cline { 2 - 3 } phương pháp ngâm & phương pháp Soxhlet \\
\hline 0,5 & $0,0702 \pm 0,0014^{\mathrm{efg}}$ & $2,0407 \pm 0,0725^{\mathrm{i}}$ \\
1,0 & $0,0734 \pm 0,0011^{\mathrm{de}}$ & $2,3176 \pm 0,0766^{\mathrm{h}}$ \\
1,5 & $0,0755 \pm 0,0023^{\mathrm{d}}$ & $2,4323 \pm 0,0777^{\mathrm{gh}}$ \\
2,0 & $0,0801 \pm 0,0046^{\mathrm{c}}$ & $2,4667 \pm 0,0943^{\mathrm{gh}}$ \\
2,5 & $0,0835 \pm 0,0008^{\mathrm{bc}}$ & $2,4750 \pm 0,0367^{\mathrm{fgh}}$ \\
3,0 & $0,0855 \pm 0,0013^{\mathrm{ab}}$ & $2,5863 \pm 0,0715^{\mathrm{fg}}$ \\
3,5 & $0,0879 \pm 0,0021^{\mathrm{a}}$ & $2,6420 \pm 0,0604^{\mathrm{ef}}$ \\
4,0 & $0,0722 \pm 0,0019^{\mathrm{def}}$ & $2,7933 \pm 0,0729^{\mathrm{e}}$ \\
4,5 & $0,0695 \pm 0,0013^{\mathrm{fg}}$ & $2,9767 \pm 0,0964^{\mathrm{d}}$ \\
5,0 & $0,0687 \pm 0,0006^{\mathrm{g}}$ & $3,0957 \pm 0,0994^{\mathrm{d}}$ \\
5,5 & - & $3,9157 \pm 0,0879^{\mathrm{a}}$ \\
6,0 & - & $3,6530 \pm 0,0552^{\mathrm{b}}$ \\
6,5 & - & $3,5097 \pm 0,0728^{\mathrm{bc}}$ \\
7,0 & - & $3,4777 \pm 0,0994^{\mathrm{c}}$ \\
\hline
\end{tabular}

Ghi chú: $\pm:$ sai số chuẩn; các giá trị trung bình trong cùng một cột theo sau có mẫu tư giống nhau thể hiện sự khác biệt không có ý nghĩa về mặt thống kê với độ tin cậy $95 \%$.

\subsection{Xác định hàm lượng naringin trong dung dịch chiết xuất}

Kết quả dịch chiết xuất sau khi được tách bằng phương pháp sắc ký giấy bản mỏng và được phát hiện vết bằng $U V_{245 n m}$ (Hình 2). Hàm lượng naringin tổng trước và sau khi sắc ký trên bản mỏng với dung môi sắc ký ethyl acetate: acetic acid: nước (10:2:1) lần lượt là $3,9157 \pm 0,0921 \mathrm{mg} / \mathrm{mL}$ và $2,8685 \pm$ $0,0532 \mathrm{mg} / \mathrm{mL}$. Như vậy, tỷ lệ naringin chiếm khoảng $73,26 \%$ trong thành phần naringin tổng. Kết quả cho thấy hàm lượng naringin trong dịch chiết xuất chiếm khoảng $73,26 \%$ và $26,74 \%$ còn lại là các hợp chất phân cực và các hợp chất phenol khác, vì các hợp chất phenol này cũng hấp thụ ở bước sóng là $283 \mathrm{~nm}$ khi đo hàm lượng naringin tổng theo phương pháp của Kuntíc et al. (2012).

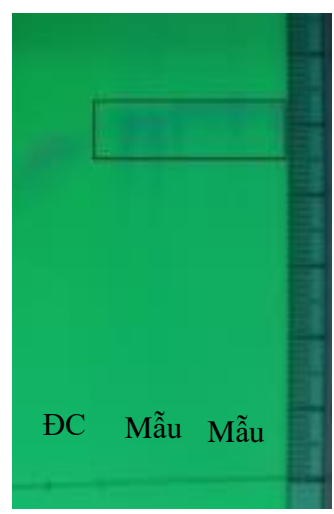

Hình 2. Vết naringin được nhận diện trên sắc ký bản mỏng 


\section{KẾT LUẬN}

Quy trình chiết xuất naringin từ vỏ bưởi Năm Roi được xác định với phần vỏ trắng được cắt nhỏ và sấy ở $65^{\circ} \mathrm{C}$ trong 24 giờ và được xay thành bột mịn. Sử dụng $15 \mathrm{~g}$ bột bưởi, gói trong giấy lọc, ngâm với dung môi (hỗn hợp ethanol và nước là $8: 2$ ) với tỷ lệ 1:14 trong 1,5 giờ ở nhiệt độ phòng. Quá trình chiết xuất naringin được thực hiện bằng phương pháp Soxhlet ở $80^{\circ} \mathrm{C}$ trong 5,5 giờ, hàm lượng naringin thu được là $2,8685 \pm 0,0532 \mathrm{mg} / \mathrm{mL}$. Kết quả nghiên cứu cho thấy tiềm năng để chiết xuất naringin từ nguồn vỏ bưởi Năm Roi nhằm tận dụng triệt để hơn nguồn phụ phẩm này và giúp làm gia tăng giá trị của trái bưởi nói chung.

\section{LÒ̀I CẢM ƠN}

Nghiên cứu được thực hiện thông qua sự tài trợ kinh phí từ đề tài nghiên cứu khoa học cấp Bộ "Nghiên cứu công nghệ sản xuất naringin và tinh dầu từ vỏ quả bưởi và xây dựng mô hình sản xuất thực nghiệm" (mã số: CT2020.01.TCT.07) thuộc Chương trình khoa học và công nghệ Bộ Giáo dục và Đào tạo "Nghiên cứu ứng dụng và phát triển công nghệ tiên tiến trong bảo quản, chế biến nông thủy sản vùng Đồng bằng Sông Cửu Long”.

\section{TÀI LIỆU THAM KHẢO}

Ahmeda, S., Khanb, H., Aschner, M., Hasana, M. M., \& Hassan, S. T. S. (2019). Therapeutic potential of naringin in neurological disorders. Food and Chemical Toxicology, 132, 110646.

Bacanli, M., Başaran, A. A., \& Başaran, N. (2015). The antioxidant and antigenotoxic properties of citrus phenolics limonene and naringin. Food and Chemical Toxicology, 81, 160-170.

Chew, K. K., Khoo, M. Z., Ng, S. Y., Thoo, Y. Y., Wan A. W. M., \& Ho, C.W. (2011). Effect of ethanol concentration, extraction time and extraction temperature on the recovery of phenolic compounds and antioxidant capacity of Orthosiphon stamineus extracts. International Food Research Journal, 18(4), 1427-1435.
Ghasemzadeh, A. \& Ghasemzadeh, N. (2011). Flavonoids and phenolic acids: Role and chemical activity in plants and human. Journal of Medical Plants Research, 5(31), 6697-6703.

Hounghton, J. P. \& Ramam, A. (1998). Laboratory Handbook for the Fractional of Natural Extracts. Chapman \& Hall.

Kanaze F. I., Kokkalou, E., Niopas, I., Georgarakis, M., Stergious, A., \& Bikiaris, D. (2006). Thermal analysis study of flavonoid solid dispersions having enhanced solubility. Journal of Thermal Analysis and Calorimetry, 83(2), 283-290.

Kuntíc, V., Pejíc, N. \& Mícíc, S. (2012). Direct spectrophotometric determination of hesperidin in pharmaceutical preparation. Acta Chimaca Slovenica, 59(2), 436-441.

Lu, Y., Zhang, C., Bucheli, P., \& Wei, D. (2006). Citrus flavonoid in fruit and traditional Chinese medicinal food ingredient in China. Plant Foods for Human Nutrition, 61(2), 57-65.

Nguyễn Hoài Thương, Phan Thanh Sang, Lê Thị Ngọc Thảo, Nguyễn Trần Anh Thư và Nguyễn Ngọc Tú Uyên. (2016). Xây dựng quy trình trích xuất naringin từ vỏ quả bưởi Citrus grandis Osbeck, họ Cam (Rutaceae) thu mua ở Cần Thơ. Đề tài nghiên cứu khoa học cấp cơ sở, Trường Đại học Cần Thơ.

Niawanti, H., Lewar, Y. S., \& Octavia, N. N. (2019). Effect of extraction time on Averrhoa bilimbi leaf ethanolic extracts using Soxhlet apparatus. IOP Conference Series: Materials Science and Engineering, 543, 012018.

Rawson, E. S., Stec, M. J., Frederickson, S. J., \& Miles, M. P. (2011). Low-dose creatine supplementation enhances fatigue resistance in the absence of weight gain nutrition. Nutrition, 27(4), 451-455.

Zarina, Z. \& Tan, S. Y. (2013). Determination of flavonoids in Citrus grandis (pomelo) peels and their inhibition activity on lipid peroxidation in fish tissue. International Food Research Journal, 20(1), 313-317. 